\title{
Public Health Themes in Survival Through Design: A Son's Appreciation
}

Raymond Richard Neutra

OPINION

Keywords: public health, Richard Neutra, wellbeing

We received and we gladly publish this opinion piece by Dr. Raymond Richard Neutra, as a cross-disciplinary perspective about the research by his father, Richard Neutra, on the broader issue of public health through design. We found this contribution a fitting overture to the contents of this issue, featuring current research on a healthier habitat. [MS]

The Neutra Institute for Survival Through Design is about to republish my father's book, Survival Through Design. It will have a scholarly forward by the historian Barbara Lamprecht relating the book's concerns to current research on neuroscience and the environment. When it first came out in 1953, my own reading of this book as a junior high school student started me on my career in medicine and environmental public health. On reading it again, I am at first overcome by the tsunami of my father's seemingly unconnected speculations, free associations, and insights. As a young person, I encountered them not only in this book but in decades of conversations with my father. Stepping back, it dawns on me that the book does have themes and that exposure to these themes that my father applied to architecture and city planning, prepared me to be receptive to similar themes in medicine and public health. Indeed, my father thought that architecture had much to learn from medicine and public health. So, I am now realizing that most of the ideas and free associations in this book can be organized into the following themes that fit both the design and the environmental health domains: 
- Accelerated Muddling: Humankind is continuing to muddle towards an unnatural and dangerous world of its own making.

- Designing despite the Doubters: Just because our treatment plans and designs do not always work out or they have unanticipated adverse side effects, does not mean that we should just muddle through. We survive better through design. Design means more than thinking up decorative elements; it means anticipating consequences and finding harmonious solutions.

- Responsibility: A designer, like a doctor, should do no harm and should, for the benefit of the client, restrain exhibitionism.

- Listen: Just as the doctor becomes skillful in taking a careful history, the designer should develop ingenuity and thoroughness in determining the needs, wants, dreams, and potentialities of individual and group clients.

- Serving Biological Individuality despite Standardization: More and more of us live in a standardized urban environment. This needs to be designed to accommodate our profound biological individuality just as medicines and medical doses need to be different for different people.

- Fuzzy and Hard: Just as hard-to-measure compassion is integral to good medical practice, so the creation of delight and wellbeing is as important as designing to accommodate what we do and how we socialize even though the effects of delight are difficult to document.

- The Effects of Delight: Just as it is possible in psychiatry to study what kind of compassionate interventions are effective, so is it possible to research what works in producing wellbeing and delight in the built environment. On closer research, these "subjective" effects turn out to have objective physiological consequences.

- Design for Results: Pay more attention to what works than to unvalidated and arbitrary rules. Trying out new things and then focusing on "what" works and "why" it works has paid off for medicine. It should have a greater role in design.

- Enduring Biology: Fashion and cultural practices vary, human biology does not: satisfy biological needs as a first priority. They date back to the hundreds of thousands of years we spent on the African Veld. This is the justification for placing nature and landscape at the center of design: to reproduce now the conditions that formed us through natural selection so long ago (Fig 1). 


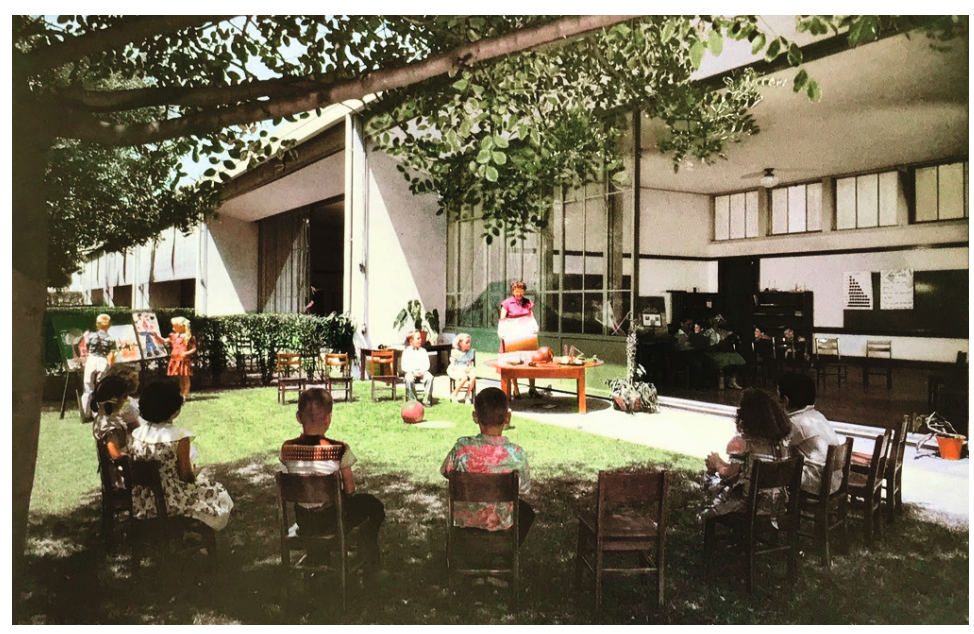

Figure 1. Corona Avenue School in Los Angeles, California (1935). The subtle everchanging input from nature and prefabricated technology provide an effective educational setting.

- The Senses: Some of the most stimulating speculations and observations in this book focus on effects that are mediated through the senses. My father reminds us of the many receptors that respond individually and in concert to the designed environment. For example:

- He points out the different feelings engendered by what is seen above us, below us, in front of us, behind us and to our side (Fig 2).

- The same environmental exposures have different impacts on the young and old.

- Some effects happen in an instant, others gradually accumulate, just as some medicines work instantly while others require long-term use.

- He points out humankind's perspective on all these topics has evolved from deep history to the present.

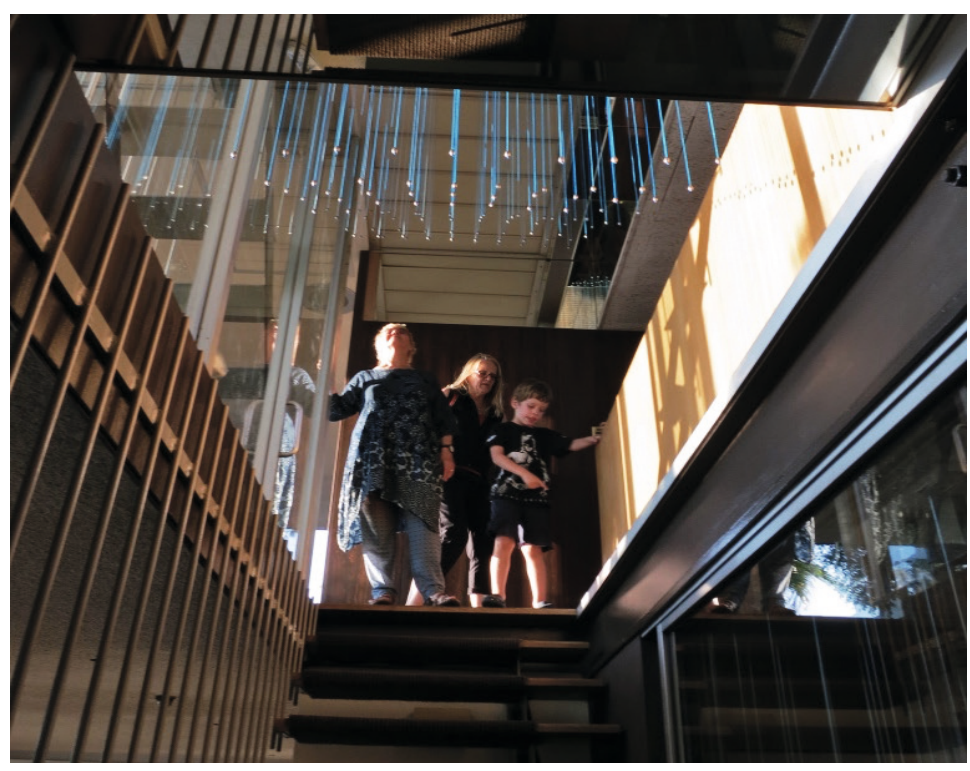

Figure 2. The stairway of the 1966 Neutra VDL Studio and Residences, with its ceiling mirrors meant to emphasize upward gaze. 
- Science and Intuition: Bringing designs or public health campaigns into fruition requires both the rational and the intuitive.

- Teamwork: Any design or public health campaign involves teams of human beings with characteristic strengths and weaknesses. Their orchestration requires knowledge, empathy, and patience (Fig 3).

- Resistance to the New: New beneficial ideas in design and in public health that deviate from the conventional inevitably meet resistance. Overcoming it requires knowledge, empathy, and patience.

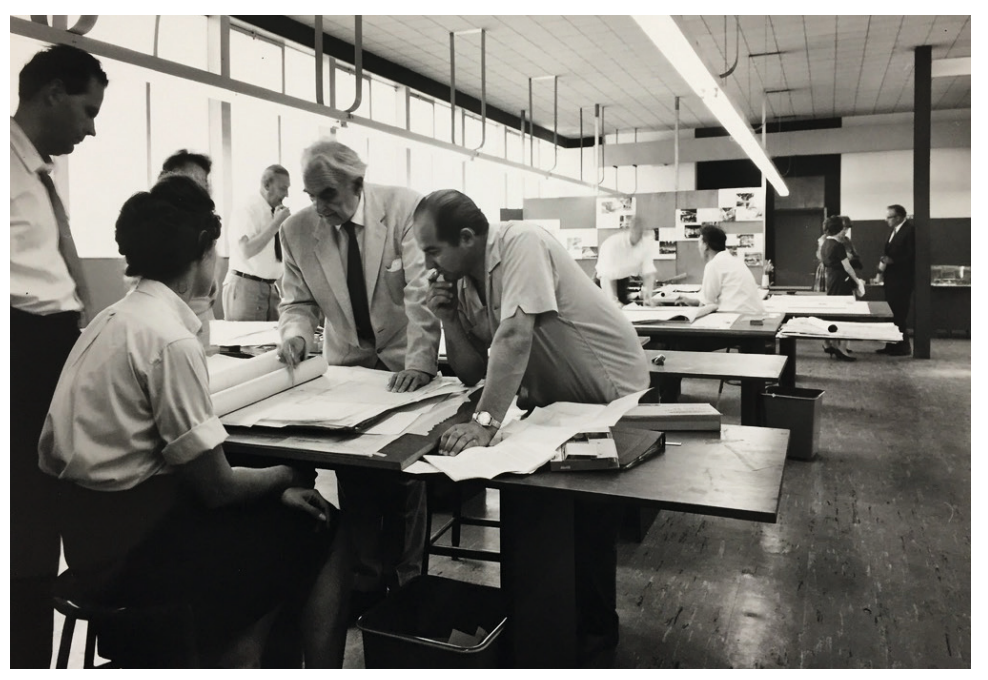

Figure 3. Teamwork Design is not a solo performance (Richard Neutra, second from right).

These are the themes my father wove together in different combinations in this book. Between the late 1930s and the date of publication in 1953, he would wake up at four o'clock in the morning and begin writing them down. This was also the hour of the day when he did his designing. The systematic interrogation of his client conferences had been held the previous evening in our living room above his office. He slept on what he had learned, and in the silence of the morning, the spatial solution suggested by the site and the client's requirements came to him as his pencil scratched on the tracing paper. As he drew, he was imagining the multi-sensory experiences created by the linked indoor and outdoor environment that was emerging on the paper before him. The preoccupations of the book were also the preoccupations of the design.

What types of scientific evidence caught my father's attention? He cited evidence gathered in various ways, ranging from anthropological observations and statistical observations to laboratory studies of mechanisms. However, it seems that his early inspiration due to reading the careful experiments of the nineteenth century psychologist Wilhelm Wundt led him to give primacy to one kind of evidence. He wanted to experimentally 
understand the mechanisms underlying "why" something was effective. For example, it would add something important for him to know "why" a view into greenery from a hospital room speeds up post-operative recovery. Only knowing from statistical evidence that such a view "does" indeed speed up post-operative recovery would not be enough. As an environmental epidemiologist, I exclusively generated the latter kind of evidence. When I had results, I usually encountered resistance from economically interested stakeholders when it came time to consider precautionary action. They wanted support from mechanistic "and" epidemiological evidence. Either type of evidence alone was not enough. For example, one industry consultant said there was no point in putting some distance between one's head and an electric bedside clock emitting magnetic fields. She said that one should be sure "beyond a reasonable doubt" that such magnetic fields could cause cancer. She required experimental evidence of a mechanism before worrisome epidemiology should influence any kind of precautionary action. But is that reasonable? Should one demand the same degree of certainty to take an easy action like that, as one would demand for a difficult action like burying all electric transmission lines? We do not make such demands in the judicial domain. In civil law, one requires only a "more likely than not" degree of proof to declare guilt, but in criminal law, before sending the accused person to prison, the proof of guilt must be "beyond a reasonable doubt." So, in law, in public health, and in environmental design, the degree of certainty required for action and the types of evidence that inform that certainty should vary according to what is at stake.

What design topics are worth the trouble of doing research on? In advocating for evidence-inspired design, my father did not say which of Vitruvius' three criteria, "firmness, commodity and delight," warranted investigation. However, my father's research examples seem to pertain primarily to Vitruvius' utility and delight. His citations included research results that rule out the use of certain design choices and some that inspire the open-ended search for new solutions. The kind of environmental epidemiology research I did in my career suggested what one should "not" do. For example, ruling out the use of lead paint since there is disutility in damaging your children's brains. But evidence can also be evocative and inspire design. For example, if evidence suggests that a modest increase in exercise can decrease the risk of obesity and diabetes, one is inspired to aim at stairway designs in an office building that lure inhabitants away from the elevators. But this, in turn, requires further evidence about what design features are likely to be alluring. And, if we are serious, it suggests a post-occupancy evaluation about stairway use, and even on rates of obesity in stairway climbers and elevator users. Is the added cost of an alluring staircase compensated by the healthy years of life that have been added?

Finally, there is an important concept missing from Survival Through Design. The philosopher David Hume pointed it out in his 1739 book $A$ Treatise of Human Nature what has since been called the "is/ought problem." 
Just because we understand what "is" a beneficial effect of a proposed intervention or design does not guarantee that we know that we "ought" to pursue it. Here is an example of this issue: My father knew that using floor-to-ceiling sliding glass doors produced a delightful extension of the ceiling and floor lines to the outdoors. When opened these large sliders created delightful acoustic and thermal experiences and allowed an enlarged domain for social functions (Fig 4).

However, it also increased the risk of not noticing that the door was closed, walking through it, shattering the glass, and severing an artery. He knew the risk of this possible adverse side effect because he shattered two such doors during photo shoots, though luckily without major injury. Nonetheless, he made a value judgement in future specifications, in which delight outbalanced safety. He continued to specify those doors. To his credit, none of the inhabitants of my father's three hundred projects has experienced a serious sliding door accident or death. So, knowing what works and why is only one ingredient in the choice of design. Assigning values to possible consequences and properly balancing them is the other. The balance we choose can never be immune from legitimate questioning.

My father hoped that knowing what worked and why would silence any opposition. But truths, and particularly "inconvenient truths," do not automatically tell us what we "ought" to do or overcome resistance to science-based recommendations. So, while I agree with my father that we must commit to discovering the truth about the likely consequences of the courses of action open to us, I think we have to go further. We must develop the wisdom to make explicit our view of the relative value of the possible intended and unintended consequences. Finally, we must develop the ability to convene the affected stakeholders so that they can negotiate an acceptably balanced solution as we, with them, design our way to survival.

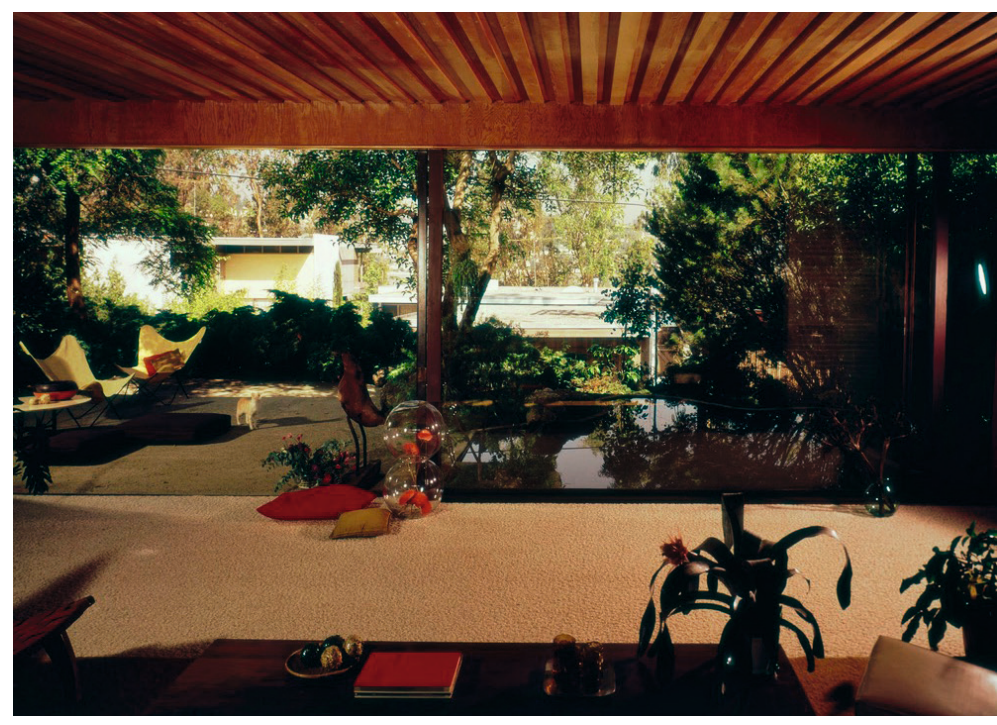

Figure 4. Glass door of The Richard and Dion Neutra Reunion House (1950). This enormous sliding glass door has prioritized delight despite a slight risk of breakage and laceration. 


\section{Credits}

Figure 1: photo by @ Julius Shulman.

Figure 2: photo by author, (c) Raymond Richard Neutra.

Figures 3 and 4: photos by (C) Julius Shulman.

Raymond Richard Neutra is a retired physician environmental epidemiologist. He is the youngest son of architect Richard Neutra and is President of the Neutra Institute for Survival Through Design (www.neutra.org). E-mail: raymondneutra@gmail.com 